\title{
Benign fibrillation potentials in normal muscle and their correlation with endplate and denervation potentials
}

\author{
M. S T Ö H R \\ From the Neurologische Universitätsklinik, Tübingen, Germany
}

SUMMARY Fibrillation potentials in normal muscle are identical in origin with the 'spikes' in the endplate zone. The difference in shape is due to the site of the electrode. Both potential types are characterised by a high average maximal frequency and a very irregular discharge pattern. These properties distinguish them from the typical fibrillation potentials of the denervated muscle which show lower maximal discharge frequency, very small differences between consecutive time intervals, and slow up and down drifts in the discharge frequency. Less commonly, irregularly discharging fibrillation potentials are also observed in denervated muscle, which are exactly the same as those in the normal muscle, and which, therefore, may be assumed to have the same origin. It is only the rhythmically discharging fibrillation potentials which indicate a denervating process. The irregular fibrillation potentials, on the other hand, are of no pathological significance. The term benign fibrillation potentials is suggested for the latter.

In the endplate zone of normal skeletal muscle two types of spontaneous discharges have been recorded in electromyographic (EMG) examinations: (1) endplate noise which appears as an irregularity of the baseline and consists of monophasic negative potentials ranging from 3-60 $\mu \mathrm{V}$ (Wiederholt, 1970) which are probably identical with miniature endplate potentials (Buchthal and Rosenfalck, 1966); (2) 'spikes' or 'nerve potentials' with amplitudes ranging from $100-500 \mu \mathrm{V}$ and irregular frequency (Jones et al., 1955). The initial negative deflection of these potentials indicates that they originate at the site of the recording, the subsequent slower positive deflection indicates their propagation (Lorente de Nó, 1947; Wiederholt, 1970). These 'spikes' represent propagated action potentials which are probably induced by the synchronised occurrence of a rather large number of miniature endplate potentials (Buchthal and Rosenfalck, 1966); this is why they are also denoted as 'endplate potentials'. It has been suggested that fibrillation potentials-with a

Address for correspondence and reprint requests: Dr M. Stöhr, Neurologische Universitätsklinik, Liebermeisterstr. 18-20, D 7400 Tübingen, Germany.

Accepted 4 February 1977 positive initial deflection-which have frequently been recorded in normal muscles are generated in the same way. The different form of these fibrillation potentials could be due to the distance between the site of the electrode and the endplate (Buchthal and Rosenfalck, 1966). To verify this hypothesis I examined a large number of both potential types with respect to duration, voltage, shape, and discharge pattern. Finally, the fibrillation potentials in normal muscle were compared with those in denervated muscles to assess possible differentiating characteristics.

\section{Material and methods}

One hundred and twenty-two initial negative, mostly diphasic 'spikes' ('endplate potentials') and 216 fibrillation potentials were examined in normal muscles (without clinical or EMG signs of neuromuscular disorders) with respect to duration, voltage, number of phases, and discharge pattern. I also examined 107 fibrillation potentials in denervated muscles with an irregular discharge sequence. An analysis of rhythmically discharging fibrillation potentials in denervated muscles was considered unnecessary as this has already been investigated in detail (Conrad et al., 1972). The 
muscles investigated showed significant signs of more or less severe denervation secondary to different peripheral nerve lesions (weakness, wasting, and EMG criteria of neurogenic involvement - diminished activity in spite of full effort; percentage of polyphasic potentials more than $12 \%$; and a greater than $20 \%$ increase in mean duration of motor unit potentials).

The spontaneous action potentials were recorded at different oscilloscope sweep velocities using concentric electrodes (Disa 13 L 13 and $13 \mathrm{~L} 50)$ on a two or three channel electromyograph (Disa 14 A 30). In assessing the discharge pattern, only those potentials were selected for calculation which occurred in a series of at least 30 consecutive waves. For every series the minimal and maximal time interval between two consecutive potentials was determined and the minimal, maximal, and average discharge frequencies were calculated from the results obtained.

\section{Results}

The Table shows that the average duration of spontaneous action potentials was almost identical in the three types and that the average amplitudes were of the same order. A good correlation was also found in the discharge pattern: both the discharge frequency and the sequence of the potentials, which showed considerable variance in the consecutive time intervals, were very similar (Fig. 1). In most instances, the discharge frequency was highest immediately after insertion of the electrode; it then declined gradually, but in irregular sequence. Frequently, a single or recurring secondary increase in frequency was observed. In several cases a minimal displacement of the electrode changed the fibrillation potentials in
Table Parameters and discharge frequencies of the three types of spontaneous activity investigated.

\begin{tabular}{|c|c|c|c|}
\hline & $\begin{array}{l}\text { Diphasic spikes } \\
\text { with negative } \\
\text { onset } \\
\text { ('endplate' } \\
\text { potentials') }\end{array}$ & $\begin{array}{l}\text { Fibrillation } \\
\text { potentials in } \\
\text { normal muscles }\end{array}$ & $\begin{array}{l}\text { Fibrillation } \\
\text { potentials with } \\
\text { an irregular } \\
\text { discharge } \\
\text { pattern in } \\
\text { denervated } \\
\text { muscles }\end{array}$ \\
\hline \multicolumn{4}{|l|}{ D.uration (ms) } \\
\hline Average & 2.8 & 3.1 & 3.0 \\
\hline $\begin{array}{l}\text { Standard } \\
\text { deviation (SD) }\end{array}$ & 0.8 & 0.7 & 0.8 \\
\hline \multicolumn{4}{|l|}{ Voltage $(\mu \mathrm{V})$} \\
\hline Average & 396 & 416 & 49() \\
\hline SD & 490 & 421 & 443 \\
\hline \multicolumn{4}{|c|}{ Time intervals (ms) } \\
\hline \multicolumn{4}{|l|}{$\begin{array}{l}\text { Minimal time } \\
\text { interval }\end{array}$} \\
\hline Average & 33 & 41 & 52 \\
\hline SD & 41 & 44 & 49 \\
\hline \multicolumn{4}{|l|}{$\begin{array}{l}\text { Maximal time } \\
\text { interval }\end{array}$} \\
\hline Average & 240 & 292 & 341 \\
\hline SD & 217 & 269 & 398 \\
\hline $\begin{array}{l}\text { Average maximal } \\
\text { discharge } \\
\text { frequency }\left(s^{1}\right)\end{array}$ & 30 & 24 & 19 \\
\hline
\end{tabular}

normal muscles into diphasic endplate potentials 0 with negative onset (Fig. 2). The observation o के made by Buchthal and Rosenfalck (1966) that both of these potential types occur most frequently ine the distal muscles was confirmed; $84 \%$ of the 'end $\square$ plate potentials' and $81 \%$ of the fibrillation poten 80 tials in normal muscles were recorded there. Thiso क is probably due to the comparatively larger extent $\overrightarrow{0}$ of the endplate region in the distal muscles. Unlike Buchthal and Rosenfalck (1966), I did not only find fibrillation potentials confined to one of the 20 points of a normal muscle which were examined in most cases; in $34 \%$ of the cases examined fibrillation potentials were recorded at two or three different sites. a

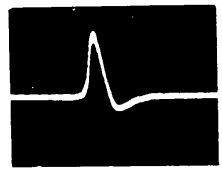

b

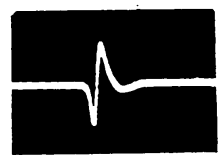

c

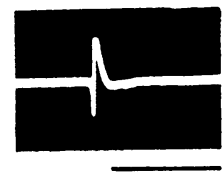

$5 \mathrm{~ms}$
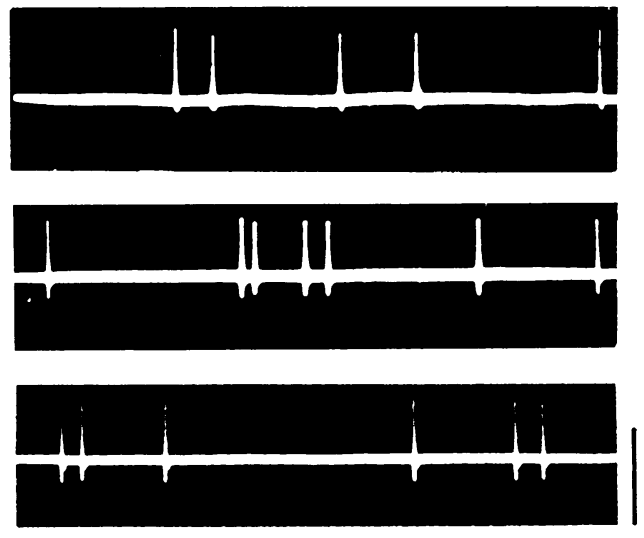

$100 \mathrm{~ms}$
Fig. 1 Discharge patterns of (a) initial negative, diphasic spikes ('endplate potentials'), (b) fibrillation potentials in a normal muscle, and (c) fibrillation potentials with an irregular sequence in a denervated muscle. (Positive deflection downwards.) 


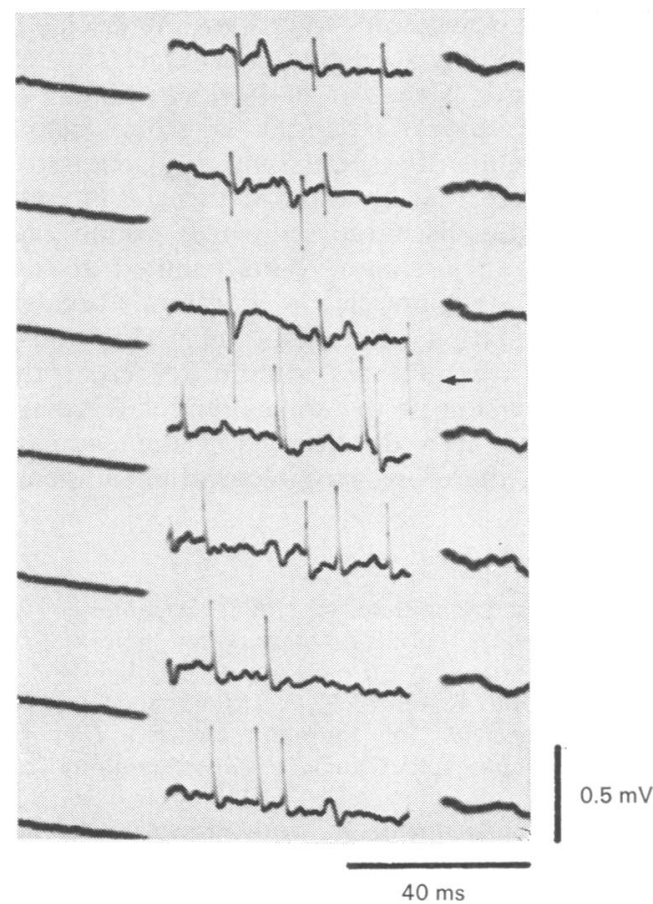

Fig. 2 Fibrillation potentials in a normal muscle; by a minimal displacement of the electrode ( - ) they change into diphasic spikes with a negative onset ('endplate potentials').

\section{Discussion}

The fibrillation potentials found in normal muscles probably have the same origin as the spontaneous diphasic 'spikes' in the endplate zone ('nerve potentials'. 'endplate potentials'). This is suggested by the good correlation between the parameters of these potentials, and in particular by the identical discharge patterns with respect to frequency and irregularity (Table. Fig. 1). The difference in shape can be explained by a different position of the electrode: if it is positioned in the endplatezone, a diphasic potential with a negative onset (endplate potential, spike) is recorded: if the electrode is at a distance from the endplate zone a diphasic or triphasic potential with an initial positive deflection (fibrillation potential) occurs (Lorente de Nó. 1947) (Fig. 1).

An observation favouring this theory is that in several cases a slight displacement of the electrode changed fibrillation potentials to endplate potentials and vice versa (Fig. 2).

There are different views as to the origin of the initial negative diphasic spikes (Jones et al., 1955; Buchthal and Rosenfalck. 1966). The common superimposition of these potent:als on endplate noise (which probably consists of miniature cnd. plate potentials (MEPP), Buchthal and Rosenfalck. 1966) suggests that when a number of MEPP occur almost simultaneously a propagating action potential is induced and propagated over the muscle fibre. As occurrence of this type of summed MEPP is a matter of chance. an irregularity in the firing sequence results. The comparatively high frequency of the spikes may be due to the mechanical stimulation of the needle electrode. because this also can induce a considerable increase in the frequency of the MEPP (Liley. 1956). If the propagated action potentials which are evoked in the endplate zone are traced to their site of origin they show an initial negative. mostly. diphasic shape (spikes, endplate potentials); if they are led off at a distance from the endplate the potentials are initially positive and usually triphasic (fibrillation potentials).

In denervated muscle there are two diferent types of fibrillation potentials. The more frequent type has been analysed by Conrad et al. (19/2) with a DEC PDP-12 computer. It shows 'extremely small differences between consecutive intervals'. and an average maximum discharge frequency of $6.3 / \mathrm{s}$ (Fig. 3). This type is also characterised by 'slow up and down drits in the spontaneous discharge frequency', attributable to generator potentials across the muscle fibre membrane, lowered firing threshold and constant sized after-potentials (Nicholls, 1956; Lüllmann, 1960; Belmar and Eyzaguirre, 1966). Less frequently fibrillation potentials are found in denervated muscle with the same discharge pattern as the fibrillation potentials in normal muscle (and therefore with the firing pattern of endplate potentials) (Table). It seems reasonable to assume the same origin for this type as the one suggested above for fibrillation potentials in normal muscles. By comparison with the rhythmical firing type the

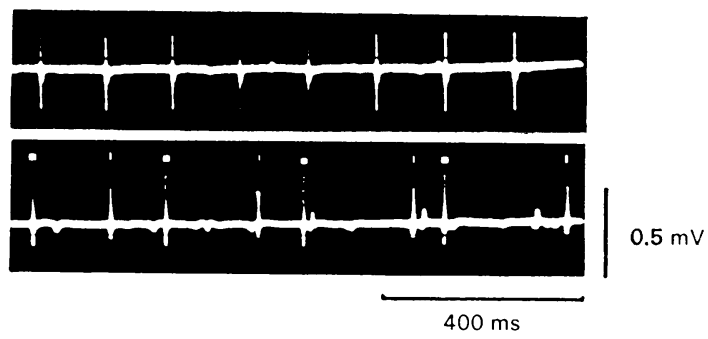

Fig. 3 Fibrillation potentials with a rhythmical firing in a denervated muscle: (note the apparent irregularity. in line 2, despite the fact that rhythmically firing potentials are present). 
average maximum discharge frequency of $19 / \mathrm{s}$ is three times as high, and no slow up and down drifts occur in the discharge frequency.

Only the rhythmically firing fibrillation potentials are pathologically significant. The fibrillation potentials which fire irregularly are unsuitable as evidence of denervation, and the term benign fibrillation potentials is suggested for this phenomenon.

Positive sharp waves also occur in a rhythmical and arrhythmical pattern (Fig. 4). Only the rhythmically firing sharp waves can be regarded as an evidence of denervation, whereas the arrhythmically firing sharp waves generally appear in normal muscles and have no pathological significance ('benign positive sharp waves'). From a practical point of view, it is very important to be aware of the types of spontaneous activity of the human muscle differentiated here. If spontaneous activity is found with the parameters indicating fibrillation potentials or positive sharp waves in the EMG in-

a

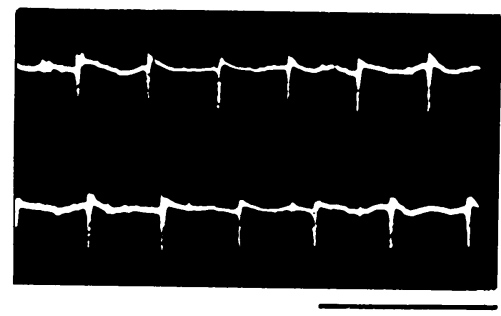

$400 \mathrm{~ms}$

b

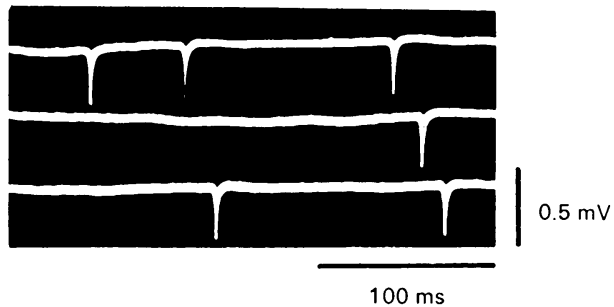

Fig. 4 Positive sharp waves (a) with a rhythmical pattern in a denervated muscle, and (b) with an arrhythmical pattern in a normal muscle. vestigation, it is necessary to analyse the discharge pattern additionally to ascertain whether the discharge sequence is regular or irregular. This can be difficult if several potentials discharge simultaneously, frequently simulating an irregularity despite the fact that rhythmical firing is present (Fig. 3). If the discharge sequences are in fact arrhythmical they cannot be attributed to denervation of the muscle in question, because irregular fibrillation potentials (and perhaps positive sharp waves) in my opinion represent the propagated version of the spikes (endplate potentials) recorded at a distance from the endplate zone and are, therefore, physiological phenomena.

\section{References}

Belmar, J., and Eyzaguirre, C. (1966). Pacemaker site of fibrillation potentials in denervated mammalian muscle. Journal of Neurophysiology, 29, 425-441.

Buchthal, F., and Rosenfalck. P. (1966). Spontaneous electrical activity of human muscle. Electroencephalography and Clinical Neurophysiology, 20, 321-336.

Conrad, B., Sindermann, F.. and Prochazka, V. J.o (1972). Interval analysis of repetitive denervation potentials of human skeletal muscle. Journal of $\frac{9}{\mathrm{D}}$ 음 Neurology. Neurosurgery. and Psychiatry, 35, 834840.

Jones. R. V., Lambert, E. H., and Sayre, G. P. (1955). Source of a type of 'insertion activity' in electro-myography with evaluation of a histologic method of localisation. Archives of Physical Medicine, 36, $\stackrel{\oplus}{2}$ $301-310$.

Liley, A. W. (1956). An investigation of spontaneous activity at the neuromuscular junction of the rat. Journal of Physiology, 132, 650-666.

Lorente de Nó, R. (1947). A study of nerve physiclogy. Studies from the Rockefeller Institute for Medical Research, 132, 384-477.

Lüllmann, H. (1960). Über die Ursache spontaner Fibrillationen denervierter Skelettmuskeln. Klinische Wochenschrift, 38, 1169-1170.

Nicholls, J. G. (1956). The electrical preperties of denervated skeletal muscle. Journal of Physio'ogy, 131, 1-12.

Wiederholt. W. C. (1970). 'End-plate noise' in electromyography. Neurology (Minneapolis), 20, 214-224. 